\title{
Biosynthesis of silver nanoparticles and exopolysaccharide using novel Thermophilic strain (Ts-1) of Bacillus amyloliquefaciens.
}

\author{
Thota Sharath Chandra, Bathini Sreelatha* . \\ *bslathabathini@gmail.com \\ Department of Biotechnology, \\ Chaitanya Degree and Postgraduate College (Autonomous), \\ Kishanpura, Warangal, TS, INDIA.
}

\author{
Abbreviations \\ AgNp's - Silver Nanoparticles \\ EPS - Exopolysaccharide \\ Uv - Ultraviolet \\ EDAX- Energy Dispersive X-ray Spectroscopy \\ SEM - Scanning electron microscopy \\ FTIR - Fourier Transform Infrared Spectroscopy \\ NAM - Nutrient Agar Media \\ YpSs - Yeast powder Soluble Starch \\ YePD - Yeast extract Peptone Dextrose
}

\begin{abstract}
In the developing world, Nanotechnology became an efficient method in therapeutics, antimicrobials, diagnostics, catalysis, microelectronics, and high sensitivity biomolecular detection. As well as on the other hand, Exopolysaccharides are biopolymers which are also widely used in food formulation, bio- flocculants, bioabsorbents, drug delivery agents. As the chemical methods of synthesizing nanoparticles and polymers are environmentally risky, costly, and toxic. In the present study, we focused on production, purification, and characterization of silver nanoparticles (AgNPs) and exopolysaccharide (EPS) by eco-friendly, extracellular biosynthetic methods using novel thermophilic Bacillus amyloliquefaciens strain Ts- 1 . This strain was isolated from soil samples by employing pour and spread plate techniques. After obtaining pure culture, the bacterium was used for the synthesis of AgNPs and EPS. Nanoparticles were synthesized from $\mathrm{AgNO}_{3}$ by using reducing agents secreted by bacteria, and Exopolysaccharide biosynthesis is carried out in three steps by the organism in the presence of a carbon source. Synthesis of colloidal AgNPs and EPS was monitored by UV-Visible spectroscopy and Visual observation, respectively. SEM, Edax and FTIR were performed for the characterization of the AgNPs and EPS such as their size, morphology and composition and we also showed the catalytic activity of AgNps in degradation of methylene blue.
\end{abstract}

Keywords: Nanoparticles, Thermophiles, Bacillus, Exopolysaccharide, Methylene Blue, Degradation. 


\section{Introduction}

Nanoparticles are the particles with a size range of $1 \mathrm{~nm}-100 \mathrm{~nm}$. During the past few years, silver nanoparticles are among the most effective antimicrobial agents as mentioned in the original research article (Deljou.A et al. 2016) Nanoparticles are also widely used in diagnostics recently, gold nanoparticles are used in Detection of SARS-CoV-2 (Moitra et al. 2020). We know that physical and chemical techniques involved in synthesis of metal nanoparticles are very costly, toxic as well as not so efficient. Chemists and Biologists gathered to synthesis nanoparticles in an ecofriendly way of synthesizing metal nanoparticles using plants, bacteria, fungi, algae and yeast (Deljou.A et al. 2016) (Vilchis-Nestor et al. 2008)(Gholami-Shabani et al. 2014) (Govindaraju et al. 2008) (Kowshik et al. 2002).

Polysaccharides synthesized by bacteria were classified into three types based on their biological role. Like, glycogen - which is an intracellular polysaccharide that is stored inside the cell, K30 O-antigen - a polysaccharide which is capsular and closely linked to the cell surface, and cellulase - extracellular polysaccharides or exopolysaccharides which are secreted out of the cells ( wang et al. 2014)(Fontana et al. 2015). Biopolymers like EPS were not only produced by bacteria, also produced by plants, algae, fungi and yeast. (Gientka et al. 2015) (Dilna et al. 2015). Exopolysaccharides (EPSs) are heavy in their molecular weight and biodegradable (Sanalibaba et al. 2016). The production of EPS in bacteria carried out by four mechanisms which clearly described earlier by (Schmid et al. 2015). Application of EPSs is popular in various industries such as medicine, pharmaceuticals and cosmetics. Also, microbial EPSs can be used in the food industry (Bajpai et al. 2016) in some of the areas of usage are like controlling the viscosity and modify flow, Improve texture, mouthfeel, Thickeners softeners, Low calories food products, Dietary fibres, Films and coating agents, Frozen food icing, Moisturizing agents etc.

In the last two decades, The bacterial based product production has globally increased and got a good impact on their usage. Thus production is carried out in high quantities. In industries, they usually use large containers to make the desired product where temperature rises more than $40^{\circ} \mathrm{C}$ which is lethal to 'mesophiles and psychrophiles' which has to be controlled using high-level cooling machinery to cool the temperatures. To avoid these unwanted cooling systems which consume space, economy and skilled labour, many scientists were switching their focus on thermophiles that can withstand high temperatures and continue their metabolisms as usual without any lag. Many of Thermophilic enzymes are scientifically and industrially important. Thus exploration, identification and production of thermophiles and its products were increased.

Hence, In the present study, we are involved in the production of silver nanoparticles and exopolysaccharides from a thermophilic bacterium and also checked the degradation of methylene blue using AgNPs as a catalyst.

\section{Materials and Methods}

\section{Media}

The media used for enrichment and isolation of thermophilic bacteria is NAM (Nutrient agar media) and Emerson YpSs (Yeast Extract Soluble Starch) media. After trying with many other bacterial nutrient media, we got to know that YpSs broth is the best nutrient composition for this bacteria to produce EPS, and the Nutrient broth is good for the synthesis of AgNPs.

\section{Isolation and Identification}


Soil samples were collected from five different places of Ramky Enclave's litter dump yard "17.973517 N $79.610447 \mathrm{E} "$ where temperature varies up to $40^{\circ}-45^{\circ} \mathrm{C}$. Samples were serially diluted and cultured using the pour plate method and spread plate method and incubated at $45^{\circ}-50^{\circ} \mathrm{C}$. The cultures were then sub-cultured on the NAM and YpSs agar plates for further studies using streaking. These colonies were observed for Gram's nature, and preliminary identification was made using biochemical methods, as stated in Aneja's manual. Further, the strain was identified by 16 s rRNA sequencing.

\section{Synthesis of Silver nanoparticles}

For the biosynthesis of silver nanoparticles, the selected bacterial isolate was inoculated into a 250-ml Erlenmeyer flask containing $100 \mathrm{ml}$ sterile nutrient broth. The cultured flasks were incubated on a rotating shaker set at $200 \mathrm{rpm}$ for $48 \mathrm{hrs}$ at $45^{\circ} \mathrm{c}$ temperature. After incubation, the culture was centrifuged at 12,000 rpm for $10 \mathrm{~min}$. The supernatant was collected and used for extracellular production of silver nanoparticles by mixing equal volume of filter-sterilized $\mathrm{AgNO}_{3}$ solution at $1000 \mathrm{uM}(1 \mathrm{mM}), 5000 \mathrm{uM}(5 \mathrm{mM}), 10000 \mathrm{uM}(10 \mathrm{mM})$ of final concentrations. The reaction mixture was incubated on a rotating shaker $(200 \mathrm{rpm})$ at room temperature for a period of $48 \mathrm{hrs}$ in the dark, and control also maintained (without adding AgNO3 solution to the cell-free supernatant). Visual observation was conducted periodically to check for the nanoparticle formation. Further characterization was performed for produced nanoparticles (Krishna et al. 2015).

\section{Extraction and Purification of EPS}

Extraction and purification of EPS carried out in the same process described by (Aparna et al. 2017).

\section{Characterization of AgNps \& EPS}

The UV-visible spectrophotometer is used to observe the Plasmon absorbance in the range of 350-470 nm for the conformation of nanoparticle synthesis. Synthesized silver nanoparticles and exopolysaccharide size, shape and structural morphology are observed by Scanning Electron microscopy. EDAX is used to know the elemental composition of synthesized AgNps and EPS. The biotransformed products present in the extracellular filtrate were measured using Fourier Transform Infrared spectroscopy. For FTIR samples were freeze-dried and Diluted with potassium bromide in the ratio of 1: 100 and recorded with diffuse reflectance mode attachment in the range of 400$4000 \mathrm{~cm}-1$ at a resolution of $4 \mathrm{~cm}-1$.

\section{Catalytic application in dye degradation}

Methylene blue is a heterocyclic aromatic chemical compound with molecular formula $\mathrm{C}_{16} \mathrm{H}_{18} \mathrm{C}_{1} \mathrm{~N}_{3} \mathrm{~S}$. To investigate the catalytic activity of AgNPs, reduction of methylene blue was carried out using silver nanoparticles and incubating them for 48hrs. The extent of degradation of methylene blue dye using AgNPs as a catalyst was monitored by UV-Visible spectroscopy by measuring absorbance maxima of dyes at different time intervals $0 \mathrm{~h}, 1 \mathrm{~h}$, $3 \mathrm{~h}, 6 \mathrm{~h}, 9 \mathrm{~h}, 12 \mathrm{~h}, 24 \mathrm{~h}$ and $48 \mathrm{~h}$. A control set was maintained without AgNPs for dye and measured for absorbance. (Jyoti, K., \& Singh, A. 2016).

\section{Results \& Discussion}




\section{Strain Isolation and Identification}

The bacterium is identified by a series of biochemical tests and confirmed as gram-positive (Fig.1.b), Rod-shaped, endospore and pellicle forming (Fig.1.c) aerobic bacteria. As well the bacterium was found to be Catalase positive which can actively grow at $45^{\circ}-50^{\circ} \mathrm{C}$ and can survive at $33^{\circ}-37^{\circ} \mathrm{C}$ (Fig.1.a.) According to the Aneja manual (Aneja et al. 2007), the biochemical results showed the present organism belongs to the genus Bacillus. Further, To find the species, it was sent for DNA sequencing which on the investigation of sequence through NCBI Blast Algorithm gave 98\% homology to the Bacillus amyloliquefaciens, and this was submitted to the Genbank with a new strain name Thermophilic strain "Ts-1" with an accession number (MK553811.1). There are different strains of Bacillus amyloliquefaciens which are mesophiles; this is the first-ever report reporting Bacillus amyloliquefaciens strain Ts-1 as a thermophile that can grow above $45^{\circ} \mathrm{C}$. Strain TS- 1 was isolated and cultured accidentally on YePD media while isolating thermophilic fungi. We mistook it as yeast in the beginning till Grams and Biochemical tests were done.

\section{Fig.1 Isolated Strain TS-1}

(a) Stain TS-1 on YePD agar plates one on the top is incubated at $330-37 \mathrm{oC}$ and another is incubated at $450-$ $50 \circ \mathrm{C}$

(b) Gram-positive rods

(c) A thick layer of Pellicle is formed on the YpSs broth when it is not incubated in a shaker

\section{Synthesis and extraction of AgNps \& EPS}

The synthesis of AgNPs was easily noticed due to the colour change of the cell-free supernatant. As in the previous studies that involved silver nanoparticles production suggests the same where the supernatant with AgNO3 converts into brown colour on the synthesis of silver nanoparticles (Fig.2.b). While in control, the Cell-free supernatant remains in the light yellowish colour as same as broth colour (Fig.2.b). (Ahmed s. et al. 2015) (Guangquan Li. et al. 2012) (Deljou.A et al. 2016)

EPS can be observed as an opaque white substance due to precipitation after addition of absolute alcohol to the cellfree supernatant. EPS on drying it becomes light brown coloured powder.

Fig.2 (a) UV Visible spectrum of AgNps. (b) visual colour changes from yellow to brown

\section{Characterization of AgNps \& EPS}

\section{Uv-Vis Spectral analysis}

From the addition of $\mathrm{AgNO}_{3}$ to the supernatant, the synthesis of silver nanoparticles begins where we can observe a peak at 419nm (Fig.2.a) which gradually strengthens till 24hrs that describes the Plasmon absorbance of synthesized AgNPs which is a direct confirmation of the nanoparticles synthesis. Silver nanoparticles synthesized using $Z$. armatum leaves extract also showed the absorbance peak at $419 \mathrm{~nm}$ (Jyoti et al. 2016). In the study carried out by (Rehab et al. 2019) Surface Plasmon resonance of the AgNPs and the blue shift was observed from 428 to $422 \mathrm{~nm}$. Size, morphology, shape, composition, and dielectric environment of the synthesized nanoparticles influence the Surface plasmon absorbance band.

\section{Scanning electron microscope (SEM)}

It is evident that synthesized nanoparticles have a variation in particle sizes (Fig.3.d,e) and the average size estimated was $20 \mathrm{~nm}$ visually compared with the scale given on the SEM images. The particles observed to be in the 
size range from $10 \mathrm{~nm}$ to $50 \mathrm{~nm}$ (Fig.3.c), which seemed to increase as the concentration of $\mathrm{AgNO}_{3}$ increased (Fig.3.c,d,e).

Surface morphology of EPS is characterized by SEM, which reveals a compact, porous and coarse surface. Upon 5000x magnification EPS from Bacillus amyloliquefaciens TS-1 was observed to have the weblike structure (Fig.3.a,b). Whereas the case of EPS produced from Lactobacillus plantarum also has a porous nature described by(Sri Laxmi et al. 2017). EPS extracted from B. anthracis is compact with a smooth surface, and without any porous features (Aparna et al. 2017) such differences in the topology and morphology are mainly caused by the difference in Physicochemical properties of the difference Exopolysaccharides. Extraction, purification and preparation techniques also play a role in changing the surface morphology of EPS. (Sri Laxmi et al., 2017)

Fig.3 SEM images of (a,b)EPS \& (c,d,e)Nanoparticles
(a) EPS at 2000x magnification
(b) EPS at 5000x magnification
(c) AgNps at 10000x magnification $(1 \mathrm{mM})$
(d) AgNps at 10000x magnification $(5 \mathrm{mM})$
(e) AgNps at 20000x magnification $(10 \mathrm{mM})$

\section{Energy-Dispersive X-ray spectroscopy (EDAX)}

The EDAX Spectrum from the (Fig.4.a) reveals the highest peak of elemental Ag at $3 \mathrm{kev}$ for the silver nanoparticles suspension, which directly suggests that silver is the predominant element in the respective product. The EDAX spectrum reported by (Singh et al. 2017) also shows the peak of Ag at $3 \mathrm{kev}$ for silver nanoparticles. The carbon peak at $0.3 \mathrm{kev}$ in the spectrum corresponds to the SEM grid utilized for the study.

The elemental composition of the EPS from the EDAX spectrum showed the composition of carbon, oxygen, magnesium, aluminum, silicon, phosphorus, potassium and chlorine. Based on our literature search, there were no reports showing the surface morphology and elemental composition of the EPS produced by Bacillus amyloliquefaciens. Spectrum also showed the presence of $41.23 \%$ of carbon, $48 \%$ of oxygen further confirmed the resultant polysaccharide compounds. The present result shown in the spectrum can be supported by the article showing presence of chlorine which is also reported in the EPS produced by Streptococcus thermophilus (Sri Laxmi et al. 2017). The presence of Carbon and Oxygen in high percentages is significantly a composition mainly consisting of sugar moieties. The amounts of C, H, N, and O in EPS extracted from L. delbrueckii subsp. were 39.1, 6.2, 2.8, and 50.3, respectively(Goh et al. 2005). (Wang et al. 2019) reported the amounts of C, H, N, and S in crude EPS extracted from $L$. sakei were 39.3, 6.1, 0.4, and 0.1, respectively.

(a) Nanoparticles

Fig.4 EDAX images

(b) EPS

\section{Fourier transforms infrared (FTIR) spectroscopy.}

FTIR spectrum of nanoparticles describes the reducing \& capping agents which are involved in stabilizing the nanoparticles. The spectrum showed a number of peaks, thus reflecting its complex nature. The strong, broad absorption band at $3433.06 \mathrm{~cm}-1$ is characteristic of the alcohol/phenol $-\mathrm{OH}$ stretching vibration, carboxylic acid 
$-\mathrm{OH}$ stretch and $\mathrm{N}-\mathrm{H}$ stretching of amides. The strong peak at $1632.08 \mathrm{~cm}-1$ is characterized to $-\mathrm{NH}$ stretch of primary amines. The peaks between the ranges $1400-1000 \mathrm{~cm}-1$ were assigned to the C-F stretching. These results suggested that the biological molecules possibly perform a dual function of synthesis and stabilization of silver nanoparticles (Singh et al. 2018) (Rehab et al. 2019). The present results of the spectrum can also be supported by the data reported by (Metuku et al. 2014), who showed the FTIR spectrum confirming the presence of protein-like compounds on the surface of synthesized silver nanoparticles. Later on, confirmed that these proteins act as the capping agents which maintain the stability of nanoparticles. Finally, this spectrum reports the presence of proteins in the synthesized nanoparticles.

FTIR spectrum from Fig.4.b. showing peaks at 3432.22 is a Medium N-H stretching of primary amine, 2928.48, 2978 are a Medium C-H stretching of alkane group, 2357.76 is Strong $\mathrm{O}=\mathrm{C}=\mathrm{O}$ stretching of carbon, 1713.26 is Strong $\mathrm{C}=\mathrm{O}$ stretching of an aliphatic ketone, 1631.81 is Medium $\mathrm{C}=\mathrm{C}$ stretching of disubstituted alkene, 1432.40 is Medium C-H bending of alkane group, 881, 841, 749 are strong peaks of the beta glycosidic bond. Thus the EPS is probably constituted of monosaccharide sugar units that are interlinked with each other using beta glycosidic bonds. (Aparna et al. 2017)

(a) Nanoparticles

Fig.5 FTIR spectrum

(b) EPS

\section{Degradation of Methylene blue}

Degradation of azo dyes is important these days as these dyes are one of the main contaminants to the water. The absorption peaks of methylene blue dye in distilled water were observed at $664 \mathrm{~nm}$ in the visible region as shown in Fig-7 as MB-0h, which is also mentioned in (Jyoti et al. 2016), (Shahwan, T. et al. 2011). In the presence of AgNPs, the absorption spectrum showed dispersed peaks after the incubated time of 48 hours. This shows the degradation of methylene blue after the addition of silver nanoparticles which confirms the catalytic activity of AgNPs.

Fig.6 Uv Spectrum of Methylene blue for 48hrs of incubation with AgNPs.

\section{Conclusion}

It has been shown for the first time that the use of the thermophilic bacterium, B.amyloliquefaciens could be used for extracellular synthesis of metal (silver) nanoparticles and EPS. The stability of the nanoparticle solution could be due to the secretion of certain reducing enzymes and capping proteins by the bacterium. The advantages offered by using a bacterium mediated synthesis of metallic nanoparticles and exopolysaccharide include a toxin-free synthesis. The economic viability of the method is also the ease in handling large scale synthesis. While AgNPs produced by this bacterium also acts as a catalyst in degradation of Methylene blue dye.

\section{Acknowledgments}

I sincerely acknowledge Dr. Koteshwar Rao, Dr. G.Krishna, Dr. Aparna Banerjee for their help in analyzing the data. Authors thankful to the Head of the Department of Biotechnology, Chaitanya Degree and PG College for their persistence support during the project. Our sincere thanks to Dr. P.Sreenivasa Rao for his guidance and support during this project. 


\section{Funding}

This publication(in part) resulted from Minor Research Project (F.NO: MRP-6780/16(MRP/UGC-SERO)) funded by University Grants Commission (UGC), New Delhi.

\section{Compliance with ethical standards}

The authors confirm that there are no conflicts of interest.

\section{References}

Ahmed, S., Saifullah, Ahmad, M., Swami, B.L. and Ikram, S., 2016. Green synthesis of silver nanoparticles using Azadirachta indica aqueous leaf extract. Journal of radiation research and applied sciences, 9(1), pp.1-7.

Aneja, K.R., 2007. Experiments in microbiology, plant pathology and biotechnology. New Age International.

Bajpai VK, Rather IA, Majumder R, Shukla S, Aeron A, et al. (2016) Exopolysaccharide and lactic acid bacteria: Perception, functionality and prospects. Bangladesh J Pharmacol 11: 1-23.

Deljou, A. and Goudarzi, S., 2016. Green extracellular synthesis of the silver nanoparticles using thermophilic Bacillus sp. AZ1 and its antimicrobial activity against several human pathogenetic bacteria. Iranian Journal of Biotechnology, 14(2), p.25.

Dilna, S.V., Surya, H., Aswathy, R.G., Varsha, K.K., Sakthikumar, D.N., Pandey, A. and Nampoothiri, K.M., 2015. Characterization of an exopolysaccharide with potential health-benefit properties from a probiotic Lactobacillus plantarum RJF4. LWT-Food Science and Technology, 64(2), pp.1179-1186.

Fontana, C., Li, S., Yang, Z. and Widmalm, G., 2015. Structural studies of the exopolysaccharide from Lactobacillus plantarum C88 using NMR spectroscopy and the program CASPER. Carbohydrate research, 402, pp.87-94.

Gholami-Shabani, M., Akbarzadeh, A., Norouzian, D., Amini, A., Gholami-Shabani, Z., Imani, A., Chiani, M., Riazi, G., Shams-Ghahfarokhi, M. and Razzaghi-Abyaneh, M., 2014. Antimicrobial activity and physical characterization of silver nanoparticles green synthesized using nitrate reductase from Fusarium oxysporum. Applied biochemistry and biotechnology, 172(8), pp.4084-4098.

Gientka, I., Błażejak, S., Stasiak-Różańska, L. and Chlebowska-Śmigiel, A., 2015. Exopolysaccharides from yeast: insight into optimal conditions for biosynthesis, chemical composition and functional properties? review. Acta Scientiarum Polonorum Technologia Alimentaria, 14(4), pp.283-292.

Govindaraju, K., Basha, S.K., Kumar, V.G. and Singaravelu, G., 2008. Silver, gold and bimetallic nanoparticles production using single-cell protein (Spirulina platensis) Geitler. Journal of Materials Science, 43(15), pp.51155122 . 
Goh, K.K., Haisman, D.R. and Singh, H., 2005. Development of an improved procedure for isolation and purification of exopolysaccharides produced by Lactobacillus delbrueckii subsp. bulgaricus NCFB 2483. Applied microbiology and biotechnology, 67(2), pp.202-208.

Jyoti, K., \& Singh, A. (2016). Green synthesis of nano structured silver particles and their catalytic application in dye degradation. Journal of Genetic Engineering and Biotechnology, 14(2), 311-317.

Krishna, G.U.D.I.K.A.N.D.U.L.A., Kumar, S.S., Pranitha, V.A.D.A.P.A.L.L.Y., Alha, M.A.R.I.N.G.A.N.T.I. and Charaya, S., 2015. Biogenic synthesis of silver nanoparticles and their synergistic effect with antibiotics: A study against salmonella SP. International journal of pharmacy and pharmaceutical Sciences, 7(11), pp.84-88.

Kowshik, M., Ashtaputre, S., Kharrazi, S., Vogel, W., Urban, J., Kulkarni, S.K. and Paknikar, K.M., 2002. Extracellular synthesis of silver nanoparticles by a silver-tolerant yeast strain MKY3. Nanotechnology, 14(1), p.95.

Li, G., He, D., Qian, Y., Guan, B., Gao, S., Cui, Y., Yokoyama, K. and Wang, L., 2012. Fungus-mediated green synthesis of silver nanoparticles using Aspergillus terreus. International journal of molecular sciences, 13(1), pp.466-476.

Metuku, R.P., Pabba, S., Burra, S., Gudikandula, K. and Charya, M.S., 2014. Biosynthesis of silver nanoparticles from Schizophyllum radiatum HE 863742.1: their characterization and antimicrobial activity. 3 Biotech, 4(3), pp.227-234.

Moitra, P., Alafeef, M., Dighe, K., Frieman, M. and Pan, D., 2020. Selective Naked-Eye Detection of SARS-CoV-2 Mediated by N Gene Targeted Antisense Oligonucleotide Capped Plasmonic Nanoparticles. ACS Nano.

Rehab, H.A., Mostafa, M., Eman, H.I. and Heba, E.M., 2019. GREEN SYNTHESIS OF SILVER NANOPARTICLES USING PSIDIUM GUAJAVA LEAF EXTRACT. Journal of Environmental Science, 46(1), pp.1-19.

Sanalibaba, P. and Çakmak, G.A., 2016. Exopolysaccharides production by lactic acid bacteria. Appl. Microbiol. Open Access, 2, p.115.

Schmid, J., Sieber, V. and Rehm, B., 2015. Bacterial exopolysaccharides: biosynthesis pathways and engineering strategies. Frontiers in microbiology, 6, p.496.

Singh, H., Du, J., Singh, P. and Yi, T.H., 2018. Ecofriendly synthesis of silver and gold nanoparticles by Euphrasia officinalis leaf extract and its biomedical applications. Artificial cells, nanomedicine, and biotechnology, 46(6), pp.1163-1170.

Vilchis-Nestor, A.R., Sánchez-Mendieta, V., Camacho-López, M.A., Gómez-Espinosa, R.M., Camacho-López, M.A. and Arenas-Alatorre, J.A., 2008. Solventless synthesis and optical properties of Au and Ag nanoparticles using Camellia sinensis extract. Materials Letters, 62(17-18), pp.3103-3105.

Wang, B., Song, Q., Zhao, F., Han, Y. and Zhou, Z., 2019. Production optimization, partial characterization and properties of an exopolysaccharide from Lactobacillus sakei L3. International journal of biological macromolecules, 141, pp. $21-28$

Wang, K., Li, W., Rui, X., Chen, X., Jiang, M. and Dong, M., 2014. Characterization of a novel exopolysaccharide with antitumor activity from Lactobacillus plantarum 70810. International journal of biological macromolecules, 63, pp.133-139. 
bioRxiv preprint doi: https://doi.org/10.1101/2020.06.04.134742; this version posted June 5, 2020. The copyright holder for this preprint (which was not certified by peer review) is the author/funder. All rights reserved. No reuse allowed without permission. 

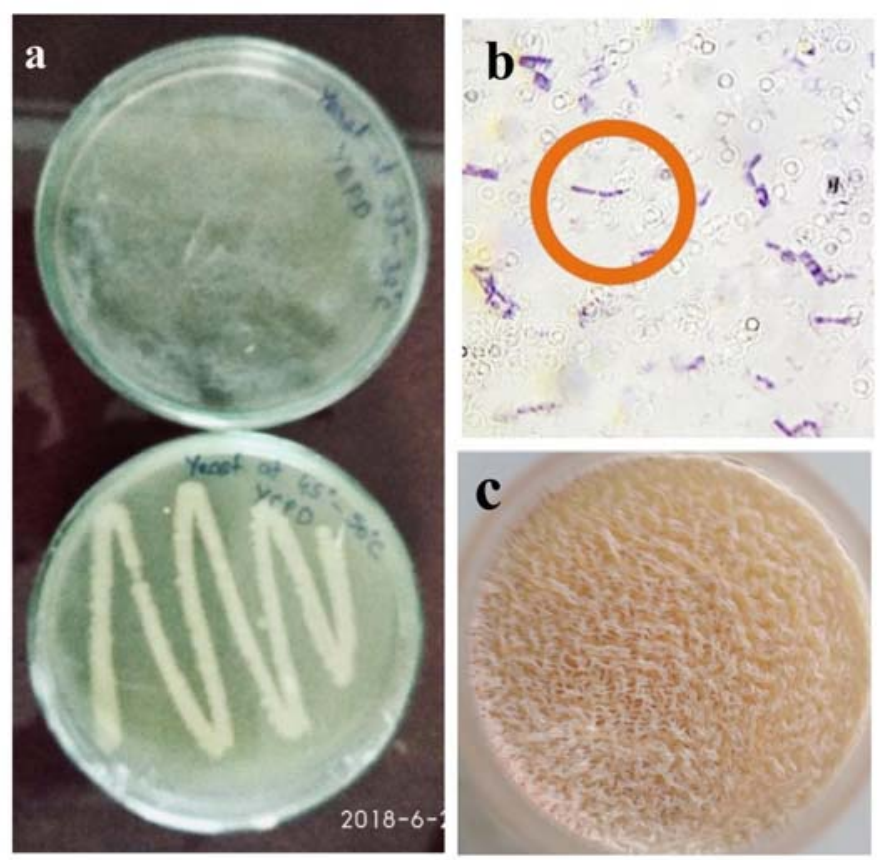

Fig. 1 Isolated Strain TS-1

(a) Stain TS-1 on YePD agar plates one on the top is incubated at $33^{\circ}-37^{\circ} \mathrm{C}$ and another is incubated at $45^{\circ}-50^{\circ} \mathrm{C}$.

(b) Gram-positive rods.

(c) A thick layer of Pellicle is formed on the YpSs broth when it is not incubated in a shaker.

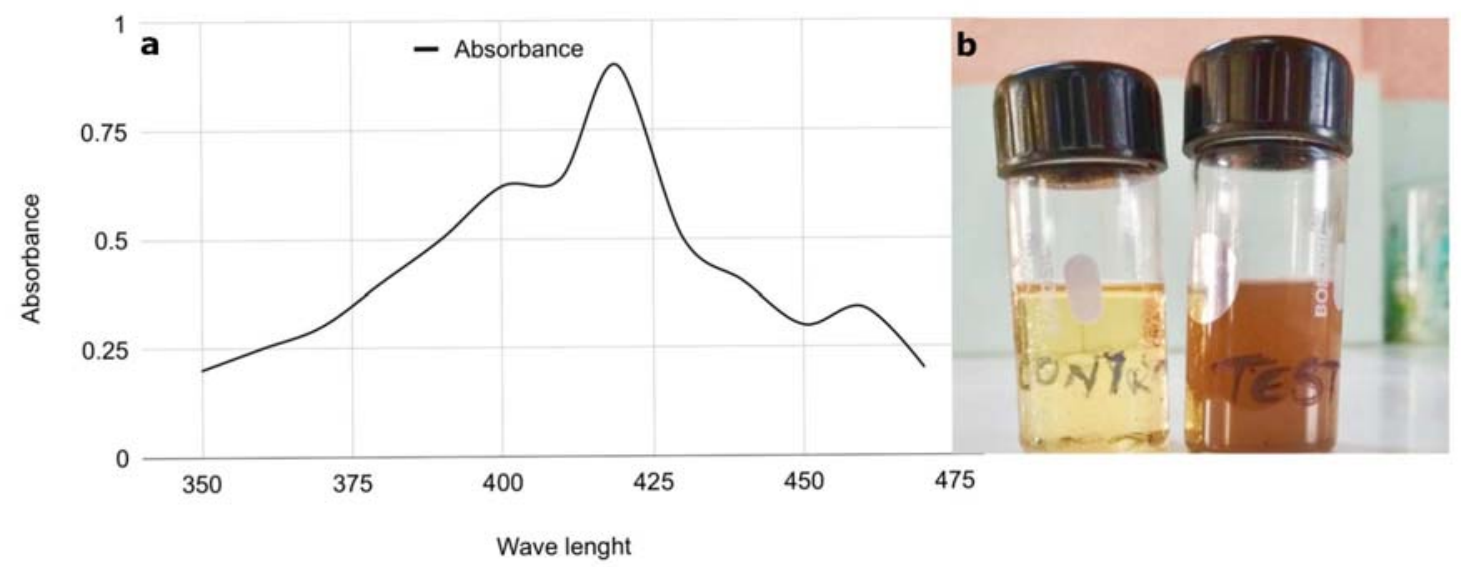

Fig.2 (a) UV Visible spectrum of AgNps. (b) visual colour changes from yellow to brown 
bioRxiv preprint doi: https://doi.org/10.1101/2020.06.04.134742; this version posted June 5, 2020. The copyright holder for this preprint (which was not certified by peer review) is the author/funder. All rights reserved. No reuse allowed without permission.
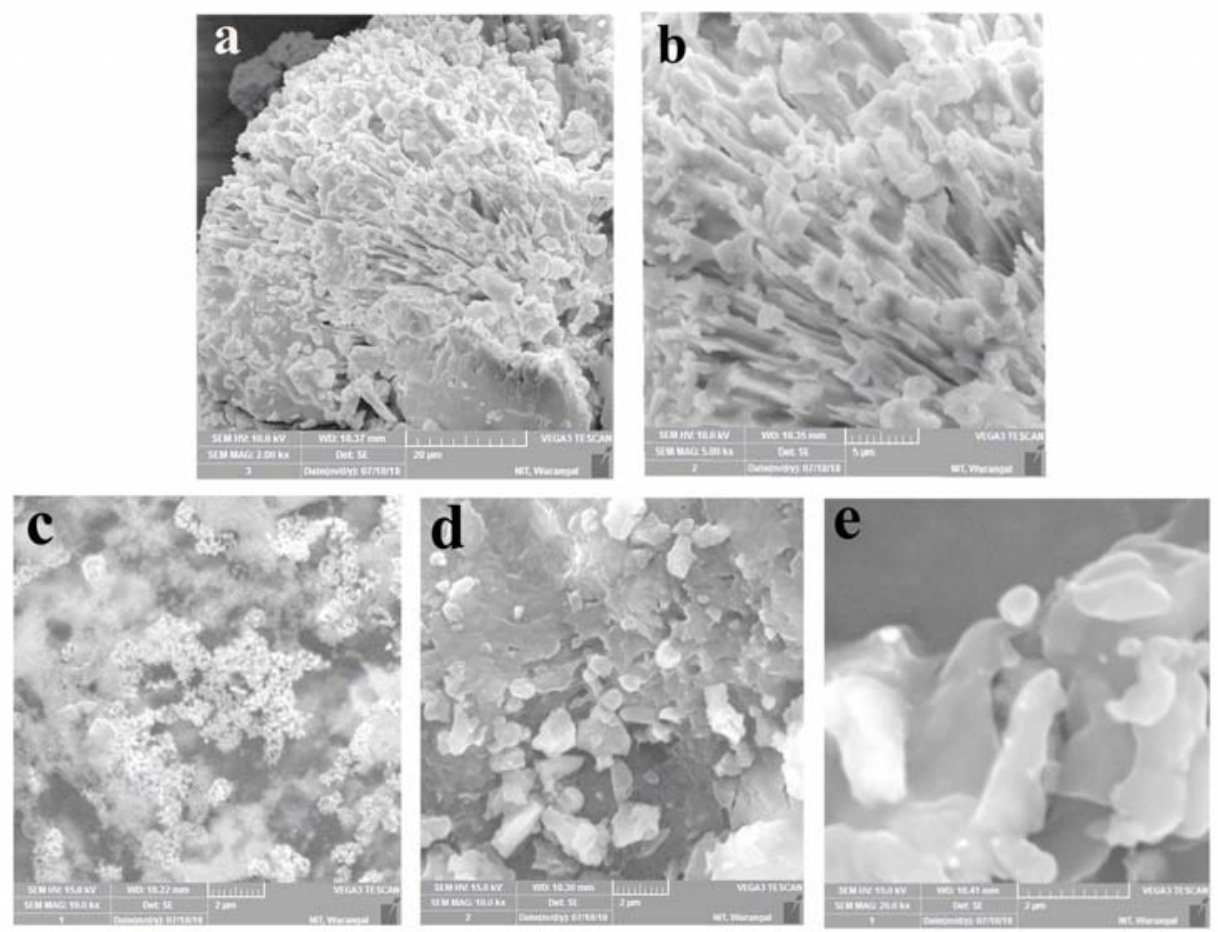

Fig.3 SEM images of (a,b)EPS \& (c,d,e)Nanoparticles

(a) EPS at $2000 \times$ magnification

(b) EPS at $5000 \times$ magnification

(c) AgNps at $10000 \times$ magnification $(1 \mathrm{mM})$

(d) AgNps at $10000 \times$ magnification $(5 \mathrm{mM})$

(e) AgNps at $20000 \times$ magnification (10mM)
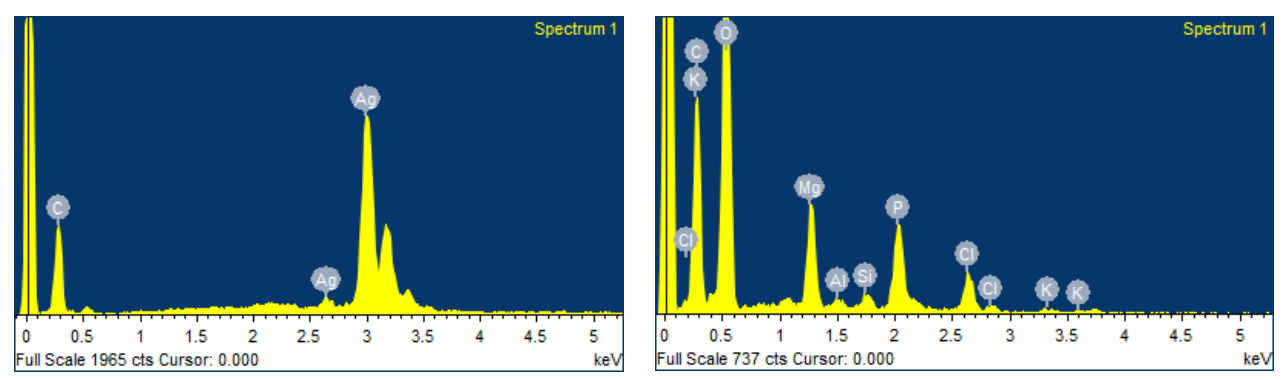

Fig.4 EDAX images

(a) Nanoparticles

(b) EPS 
bioRxiv preprint doi: https://doi.org/10.1101/2020.06.04.134742; this version posted June 5, 2020. The copyright holder for this preprint (which was not certified by peer review) is the author/funder. All rights reserved. No reuse allowed without permission.
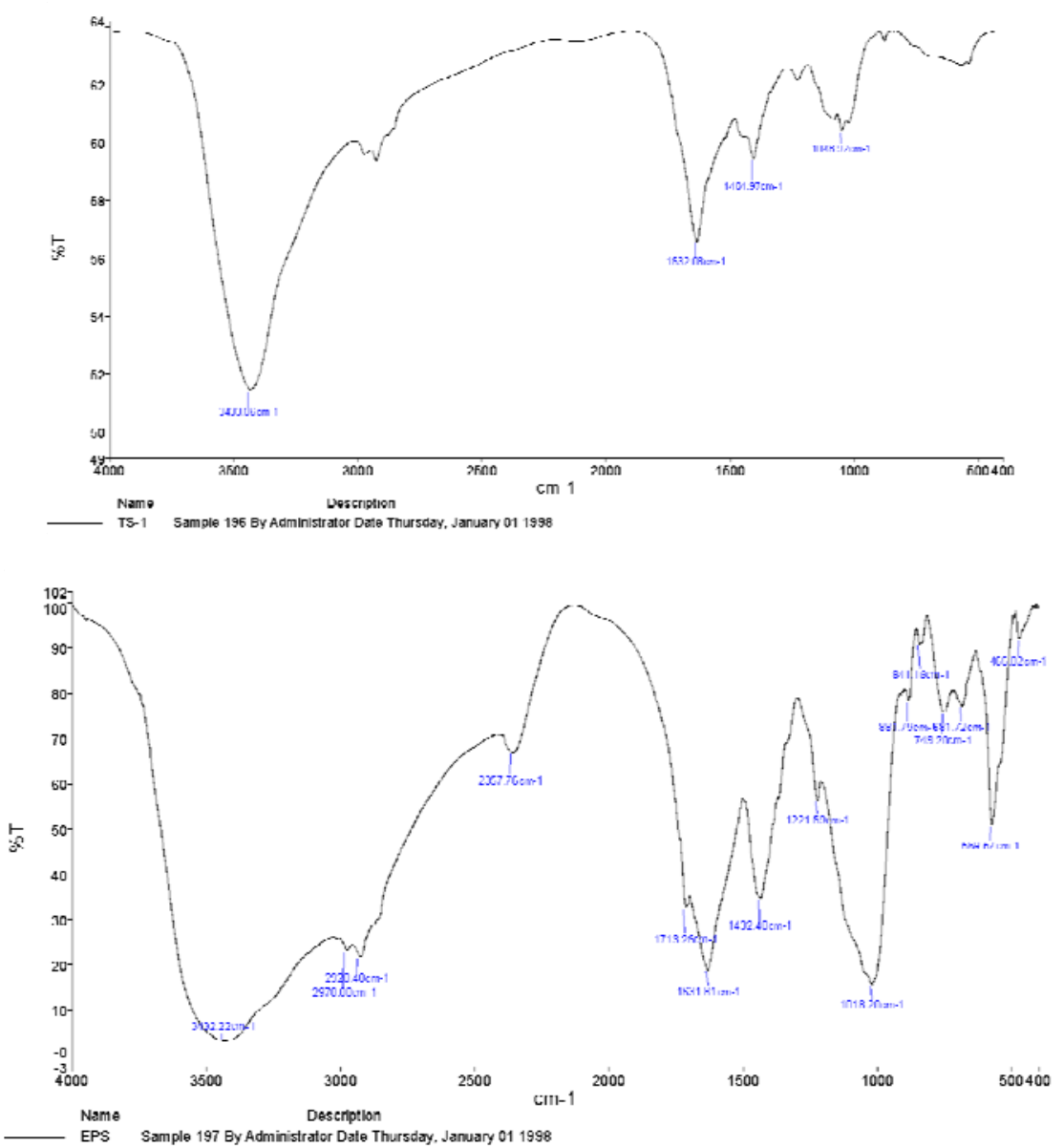

(a) Nanoparticles

Fig.5 FTIR spectrum

(b) EPS

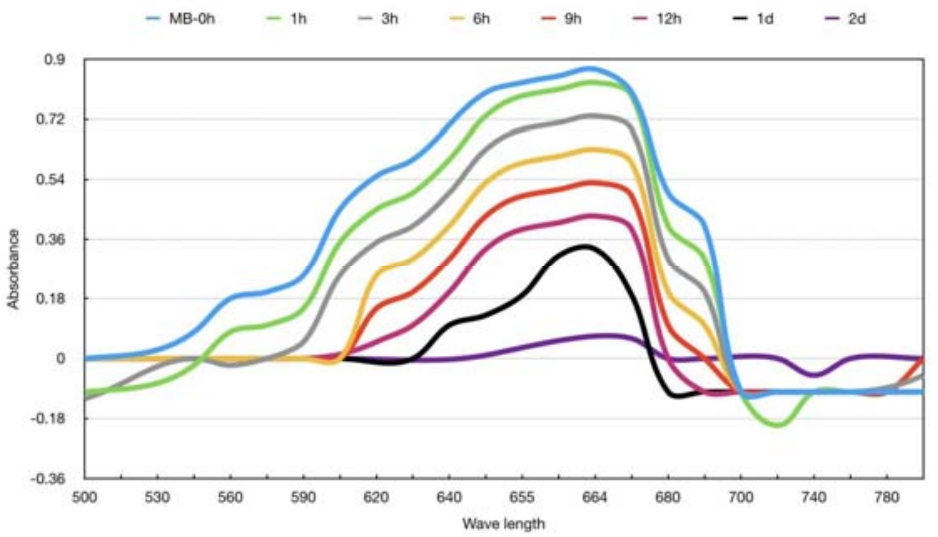

Fig.6 Uv Spectrum of Methylene blue for 48hrs of incubation with AgNPs 